\title{
The Microstructure of Aluminum-Magnesium Alloy Friction Stir Weld
}

\author{
Olga Sizova ${ }^{1,2, a)}$, Alexander Kolubaev ${ }^{1,2, b)}$, Evgeny Kolubaev ${ }^{1,2, c)}$, \\ Anastasiya Zaikina $^{2, \text { d) }}$, Valery Rubtsov ${ }^{2, e)}$, Sergey Psakhie ${ }^{1,2, f)}$, \\ Alexander Chernyavsky ${ }^{3, g}$, and Vitaly Lopota ${ }^{3, h)}$ \\ ${ }^{I}$ National Research Tomsk Polytechnic University, Tomsk, 634050, Russia \\ ${ }^{2}$ Institute of Strength Physics and Materials Science SB RAS, Tomsk, 634055, Russia \\ ${ }^{3}$ S.P. Korolev Rocket and Space Corporation "ENERGIA", Korolev, 141070, Russia \\ a) Corresponding author: ovs@ispms.ru \\ b) kav@ispms.ru \\ c) eak@ispms.ru \\ d) aaz@ispms.ru \\ e) rvy@ispms.ru \\ f) $\mathrm{sp} @$ ispms.ru \\ g) alexander.cherniavsky@rsce.ru \\ h) post@rsce.ru
}

\begin{abstract}
Friction stir weld joint of aluminum/magnesium alloy has been structurally characterized after tensile testing. A butt-weld flaw which a surface of joining between two sheets has been revealed. This defect dictates the specificity of sample's fracture in a tensile test.
\end{abstract}

Keywords: aluminum-magnesium alloy, friction stir welding, weld, microstructure, failure

\section{INTRODUCTION}

Friction stir welding is one of the newest welding processes that has been patented in 1991 [1]. The welding is performed with a rotating tool of a special shape while moving it along the butt of two metal sheets to be welded. Frictional heat caused by the interaction of the product with the tool shoulder surface and the pin is embedded into the metal, leading to the plasticization of the metal, which leads to the mass transfer rotation around the tool axis caused by frictional forces $[2,3]$.

The specificity of the friction stir welding joint microstructure is determined by the specificity of plasticized metal flow and is not similar to other welding methods. It is known from numerous relevant publications that the core part of the weld is composed of ultrafine grains generated as a result of dynamic recrystallization [3, 4]. The interface between the stirred zone and base metal is a transition from one type of structure to another and therefore is a zone where welding defects appear due to strain incompatibility.

\section{METHODS}

The tensile test and microstructural characterization of AMg5M aluminum/magnesium alloy with the thickness of friction stir welds of $5 \mathrm{~mm}$ has been carried out. Metallography has been performed using an optical microscope and the OLYMPUS LEXT 4000 laser confocal microscope and the Zeiss EVO-50 SEM instrument. For tensile test we used the UTS $110 \mathrm{M}$ test machine.

International Conference on Physical Mesomechanics of Multilevel Systems 2014

AIP Conf. Proc. 1623, 587-590 (2014); doi: 10.1063/1.4899013

(C) 2014 AIP Publishing LLC 978-0-7354-1260-6/\$30.00 


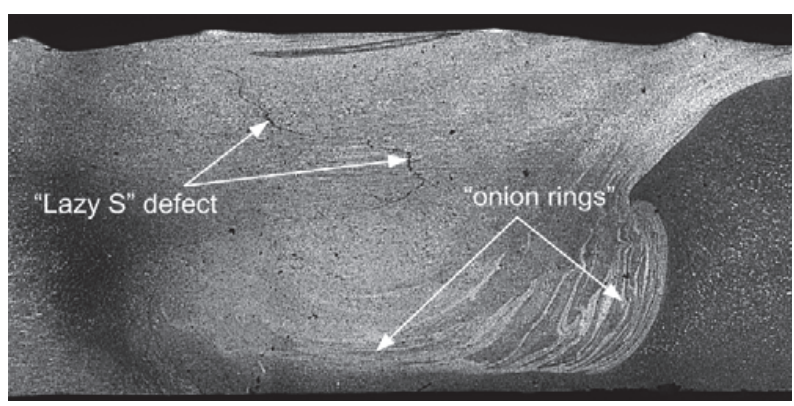

FIGURE 1. Cross section view of weld joint etched microstructure

\section{RESULTS}

The topicality of studying the friction stir welding seam structure at the interface between the stirred and base metal is stipulated by the specific type of fracturing [5]. The macrostructure of the friction stir welding sample cross section view is shown in Fig. 1. Metallographic examination of the weld zone reveals its inhomogeneous structure as being non-symmetrical with respect to the butt plane. Furthermore, a layered structure composed of alternating bands separated by intensely etched boundaries has been generated. Similar structures are known and denoted as "onion rings" $[6,7]$. There is no common opinion on their generation mechanism, however we can notice their similarity to the subsurface structures generated by sliding [8,9]. The layered structures generated by sliding originate from the interplay between the two competing processes of work-hardening and thermal softening under the strain-induced heat release [9]. Such a situation results in a successive layer-by-layer shear of the thermally softened material under the shear stress from the friction force. The eddy-like structures seen in Fig. 1 are generated by shear+rotation displacement of 3D structural units and strain incompatibility at the interface between the plasticized metal flow zone and the base metal. Finer ( 1 to $3 \mu \mathrm{m}$ in size) structural units have been found in the "onion rings" structures (Fig. 2). Such structural modification is explained by severe plastic deformation and fragmentation under recrystallization conditions. More details on generation of ultrafine grain structures could be obtained from SEM.

The generation of ultrafine grain strictures without recrystallization is the result of fast heat removal from the stirred zone to the back plate and to the environment. Indeed, the recrystallized grains have been observed in the core zone of the $35 \mathrm{~mm}$ thick friction stir welded aluminum sheets [10].

At the same time, the ultrafine grain structure was found in the vicinity of the weld/base metal interface. Such a structural feature could be provided only by the heat removal into the adjoining back plate metal. Another structural specificity of all friction stir welding joints studied (which has been revealed in the cross section view in Fig. 1) is the curvilinear defect propagated through the weld from the top to the bottom surface.

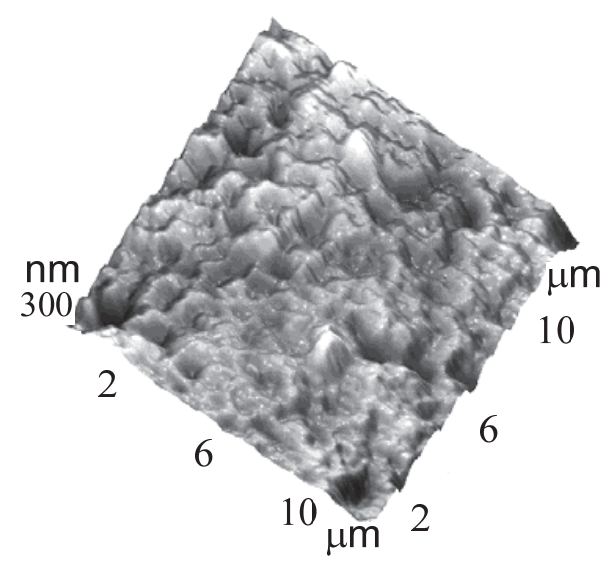

FIGURE 2. SEM image of "onion rings" zone 


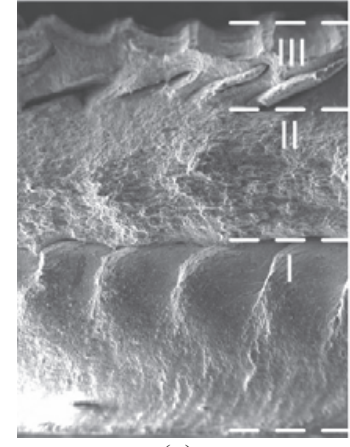

(a)

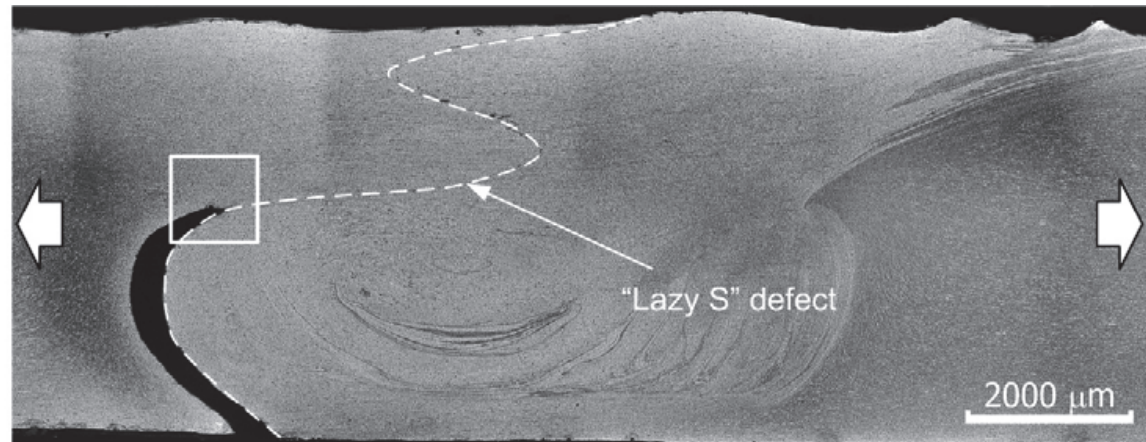

(b)

FIGURE 3. Fracture surface (a) and cross section view of friction stir welding joint after tensile test in direction shown with arrows (b)

This defect is a joint surface of two aluminum alloy sheets, which is commonly known as the Lazy S defect. When performing the tensile tests it was found that the crack propagates from the weld root along the above discussed joint surface (Fig. 3(b)).

Further propagation of the crack occurs at an angle of $45^{\circ}$ to the tensile load axis. The structural specificity of the friction stir welding joint has its effect on the fracture surface, so three different zones can be distinguished in Fig. 3(a). Zone I is found in the bottom (root) part of the weld having its smooth surface inherent to the delamination of the material. This zone corresponds to the main crack as shown in Fig. 3(b). The main crack propagates along with the Lazy S defect until it becomes practically parallel to the tensile axis.

Zone II corresponds to the viscous fracture when the main crack is stopped and further cracking is microcrack branching at $45^{\circ}$ to the tensile axis as shown in Fig. 4 which is a magnified rectangular fragment of Fig. 3(b).

Top zone III shows the delamination at some angle to the top surface of the weld joint (Fig. 3(a)).

The existence of the above-discussed zone on the fracture surface is determined by the specificity of the weld structure formation. The shoulder-driven metal flow has most effect on the top zone structure, which is much similar to the layer-by-layer plastic flow of metal observed in sliding [11]. The mass transfer in sliding is accompanied by the generation of defects, which then serve as stress concentrators for the final subsurface layer deterioration. For the friction stir welding joint this results in the delamination of material at some angle to the weld's top surface (zone III, Fig. 3(a)).

The rotation of the friction stir welding tool's pin has most effect on the metal structure formation in the middle part of the weld. The mass transfer is driven by the pin, thus forming a cylindrical surface with its axis coinciding with that of the pin. Also, there is a mass transfer in the direction vertical to the weld joint surface due to the complex shape of the pin. All this contributes to stirring and the generation of ultrafine grain structure with strength being higher than that of the base metal.

The weld root metal had minimum strength since the presence of delamination resulted in the crack cleavage even at minimum loading (Fig. 3(a)). The origination of such a defect may be related to the insufficient heating of the weld root (due to the intense heat removal into the welding machine's back plate) as well as the pin used being too short and therefore causing insufficient stirring of the metal.

Also, the oxide film on the aluminum alloy sheets has not been removed and therefore prevented good adhesion between the joint surfaces $[5,12]$. These reasons determined the low strength of the weld as compared to that of the base metal.

\section{SUMMARY}

It was established that the macroscopic weld structure shows its layered pattern similar to that obtained after a sliding test. The plastic deformation in friction stir welding produced ultrafine grain structure as a result of initial grain structure fragmentation and grain boundary slipping.

The Lazy S defect passing throughout the weld's thickness determines the character of fracturing in the tensile test when the metal is delaminated by the deficient surface already in the beginning of the test.

Three macrostructural zones have been observed on the weld fracture surface as mentioned above. 


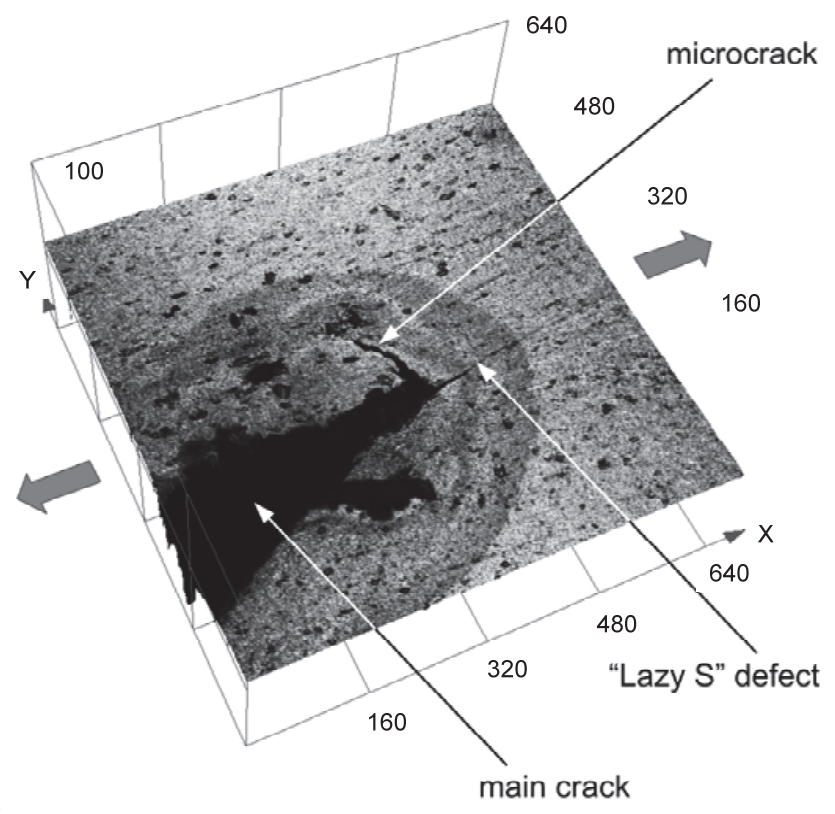

FIGURE 4. 3D image of main crack

\section{ACKNOWLEDGEMENT}

The work has been supported by Program for Basic Scientific Research of the State Academies of Sciences for 2013-2020 and the RF Ministry of Education and Science (Contract No. 02.G25.31.0063) in the framework of RF Government Order No. 218 as well as RFBR grant No. 14-08-31662.

\section{REFERENCES}

1. W. M. Thomas, E. D. Nicholas, J. C. Needham, M. G. Murch, P. Templesmith, and C. J. Dawes, G.B. patent 9125978.8 (1991).

2. F. Gratecap, M. Girard, S. Marya, and G. Racineux, Int. J. Mater. Forming 5, 99 (2012).

3. R. S. Mishra and Z. Y. Ma, Mater. Sci. Eng. R 50(1-2), 1 (2005).

4. L. E. Murr, G. Liu, and J. C. McClure, J. Mater. Sci. Lett. 16, 1801 (1997).

5. S. Kahl, Heron 55(3/4), 223 (2010).

6. J. A. Schneider and A. C. Nunes, Jr., Metall. Mater. Trans. B 35, 777 (2004).

7. K. N. Krishnan, Mater. Sci. Eng. A 327(2), 246 (2002).

8. S. Yu. Tarasov and A. V. Kolubaev, Met. Sci. Heat Treat. 52(3-4), 183 (2012).

9. V. P. Kuznetsov, I. Yu. Smolin, A. I. Dmitriev, D. A. Konovalov, A. V. Makarov, A. E. Kiryakov, and A. S. Yurovskikh, Phys. Mesomech., 16(1), 62 (2013).

10. A. N. Petrova, I. G. Brodova, I. G. Shirinkina, P. A. Nasonov, and E. V. Shorokhov, Lett. Mater. 3(2), 126 (2013).

11. O. Sizova, G. Shlyakhova, A. Kolubaev, E. Kolubaev, S. Psakhie, G. Rudenskii, A. Chernyavsky, and V. Lopota, Adv. Mater. Res. 872, 174 (2014).

12. A. Kolubaev, S. Tarasov, O. Sizova, and E. Kolubaev, Tribol. Int. 43(4), 695 (2010). 